\title{
O PROCESSO SAÚDE-DOENÇA VIVENCIADO PELOS TRABALHADORES DE ENFERMAGEM EM UMA INSTITUIÇÃO HOSPITALAR
}

[The health-illness process experienced by nursing workers ina a hospital institution]

\author{
Cleisy Mari Safiano* \\ Leila Maria Mansano Sarquis** \\ Vanda Elisa Andres Felli*** \\ Leticia Morgana Giacomozzi****
}

RESUMO: Este estudo foi realizado em um Hospital Particular em Curitiba. A população estudada foi a equipe de enfermagem composta por 56 trabalhadores. Trata-se de uma pesquisa quantitativa, com o objetivo de conhecer a saúde destes trabalhadores no processo de trabalho. Após a análise podemos considerar que estes trabalhadores são de uma faixa etária jovem de 21-30 anos (42,8\%). Encontramos comprometimento na qualidade de vida destes trabalhadores em $50 \%$ por possuírem dupla jornada de trabalho, expressos por desgaste físico, mental, fadiga, estresse e diminuição da atenção. A exposição ao ritmo acelerado de trabalho foi encontrada em $51,8 \%$. Quanto à freqüência de acidentes de trabalho encontramos uma pequena percentagem de $26,8 \%$ de trabalhadores que sofreram acidentes de trabalho nestes dois últimos anos, porém deste total $66,5 \%$ sofreram acidentes com instrumento perfurocortante. Encontramos também um grave comprometimento à saúde destes trabalhadores no que diz respeito à lesões ósteo-articulares desencadeado pela sobrecarga em relação ao esforço físico em $67,9 \%$. No que se refere ao processo saúde-doença podemos observar o desenvolvimento e aparecimento de doenças ocupacionais, sendo a cervicodorsolombalgia a mais freqüente $(89,4)$.

\footnotetext{
*Aluna do Curso de Graduação de Enfermagem da Universidade Tuiuti do Paraná.

**Enfermeira, Profa . do Departamento de Enfermagem da UFPR, aluna do Programa de Pós-graduação pela EEUSP, bolsista do CNPq.

***Enfermeira. Profa. Associada do Departamento de Orientação

Profissional da Escola de Enfermagem da Universidade de São Paulo.

${ }^{* * * *}$ Acadêmica de Enfermagem do curso de graduação de Enfermagem

da UFPR, membro do GEMSA, bolsista PIBIC - CNPq.
}

Este estudo indica a necessidade de intervenções por parte da instituições, chefias e os próprios trabalhadores com o objetivo de minimizar a exposição aos riscos de acidente de trabalho e de adquirir doenças infecto-contagiosas.

PALAVRAS-CHAVE: enfermagem, acidente de trabalho, saúde ocupacional.

\section{INTRODUÇÃO}

A globalização e as transformações capitalistas tornaram-se complexas nas relações de trabalho à lógica do Fordismo e do Taylorismo, sendo substituídas pela flexibilidade da produção, pela produtividade e adequação ao mercado. Estas transformações não podem ser entendidas como um novo modo de organização, mas sim como um avanço de recursos tecnológicos provindos da atualidade. (Collet; Rozendo, 1998). Com o avanço da tecnologia, o hospital está se tornado um ambiente com complexidade cada vez maior, contudo, mesmo em face do desenvolvimento da tecnologia, o cuidado direto ao paciente ainda exige muito esforço físico do pessoal de enfermagem (CARVALHO; LIMA, 2001).

Foi a partir da promulgação da Constituição Federal que houve uma preocupação legal em relação à saúde do trabalhador, onde as leis orgânicas foram-se atualizando e resultaram em exigências legais transformadas em portarias, leis e decretos que foram se modificando e se alterando com o objetivo de adequar a saúde do trabalhador ao ambiente laboral. A abordagem de saúde do trabalhador consiste na promoção de cuidados e proteção em seu local de trabalho, possibilitando 
minimizar riscos a que estão expostos, fazendo com que participem do seu processo de saúde, objetivando diminuir estes riscos ocupacionais (NOGUEIRA, 1983).

O termo Saúde do Trabalhador refere-se a um campo do saber que visa compreender as relações entre o trabalho e o processo saúdedoença. A saúde e a doença são consideradas como processos dinâmicos e estão estreitamente articulados com o desenvolvimento produtivo em determinado momento histórico (BRASIL, 2002).

A evolução das condições de vida e de trabalho não pode estar dissociada do desenvolvimento das lutas e das reivindicações operárias em geral, bem como das mudanças existentes no mundo do trabalho. Através de uma leitura especializada da história, conseguimos numerar os elementos necessários à reconstrução da "história da frente pela saúde", que progrediu graças a uma luta infinita (DEJOURS, 1992).

A busca no entendimento do binômio saúdedoença se destaca desde a sociedade antiga até a moderna possibilitando o entendimento que depende de diversos fatores como o modo em que o trabalhador se relaciona na sociedade, na produção de riqueza e na hereditariedade, ou seja, é através do processo de vida e a sua relação com o meio que potenciará uma pré-disposição de saúde ou de doença (DEJOURS, 1992).

Segundo Dissenha (1999), as condições de vida e trabalho geram condições favoráveis para o desgaste da saúde do trabalhador devendo ser compreendida pelas categorias ocupacionais e organizacionais. Já para Flaresso (1998), não é somente o processo de trabalho, mas também o ambiente de trabalho pode causar um estresse mental e conseqüentemente uma doença, sendo influenciado por fatores externos e internos como fatores somáticos (sexo, idade, peso, altura); ambientais (altitude, calor, frio, ruído); natureza do trabalho (intensidade, duração, técnica, horário); psicológico (motivação, ambiente de trabalho), chegando ser significativo em virtude da exposição do trabalhador aos acidentes e riscos afetando a organização e o trabalhador na sua produtividade.

A qualidade de vida no trabalho é de fundamental importância, pois o trabalho acaba tornando-se um ambiente em que define alguns aspectos vitais que podem potencializar condições relacionadas à saúde, aos equilíbrios físicos, psíquicos e emocionais. Determinará também aspectos relacionados ao bem estar e a segurança, não sendo apenas uma fonte de renda isolada conforme afirma Vieira apud Venâncio (2000).

Evoluindo no binômio saúde-doença, temos a expressão do desgaste sofrido por estes trabalhadores que se expressa pelo processo saúde-doença. Segundo Laurell; Noriega (1989), o processo saúde-doença pode comprometer a saúde e a qualidade de vida dos trabalhadores, que se expressa através da exposição às cargas de trabalho, com o aparecimento de doenças. A expressão do processo saúde-doença aponta para situações resultantes das formas possíveis dos homens desenvolverem seu trabalho e como estes trabalhadores estabelecem relações com o meio. A compreensão do processo saúde-doença e suas relações potencializa o agir dos indivíduos e também dos grupos nele inseridos (CARVALHO et al., 1998).

O processo saúde-doença não é um processo individual exclusivamente de origem e fim, nem mesmo se refere exclusivamente à dimensão biológica do homem. É um processo particular de uma sociedade que expressa no nível individual às condições coletivas de vida resultantes das características concretas dos perfis de produção. Os processos de trabalho são as expressões individuais do modo de produção da sociedade aproximando o pólo doença não apenas dos sofrimentos físicos, mas também dos psíquicos, morais e éticos (EGRY, 1996).

Considerando a relevância do tema e a escassez de pesquisas científicas desenvolvidas entre os trabalhadores da enfermagem enfocando a qualidade de vida no trabalho e as condições de saúde apresentadas por estes trabalhadores, este estudo, tem como objetivo a classificação da qualidade de vida no trabalho de enfermagem em um hospital particular de Curitiba, e a reflexão a cerca deste assunto.

\section{MATERIAL E MÉTODO}

Este estudo foi realizado em um Hospital Particular da cidade de Curitiba. As unidades escolhidas para o desenvolvimento deste estudo foram aquelas em que os trabalhadores de 
enfermagem prestam assistência aos clientes clínicos e cirúrgicos. A população estudada foi a equipe de enfermagem destas respectivas unidades com 66 trabalhadores distribuídos nas 24 horas de assistência integral ao cliente, sendo que participaram desta pesquisa 56 trabalhadores.

Trata-se de uma pesquisa quantitativa. Utilizou-se um questionário com perguntas fechadas para o conhecimento sobre o processo saúde-doença vivenciado por estes trabalhadores. Com base na Resolução do Conselho Nacional de Saúde sobre pesquisa envolvendo Seres Humanos, n 196/96, o trabalho iniciou-se após a autorização do Comitê de Ética e os 56 trabalhadores que aceitaram participar da pesquisa através do instrumento de avaliação, assinaram o termo de Consentimento Livre e Esclarecido, aceitando a participação.

\section{RESULTADOS E DISCUSSÕES}

Encontramos no estudo uma prevalência de trabalhadores casados (64,3\%), e do sexo feminino $(67,9 \%)$. Estes dados somados ao processo de trabalho podem contribuir no aumento da exposição aos riscos aos agravos á saúde, pois muitas vezes estes trabalhadores sobrepõem jornadas de trabalho associadas aos outros compromissos, acarretando uma maior sobrecarga de trabalho e conseqüentemente uma maior exposição ao acidente de trabalho, doenças ocupacionais e riscos ocupacionais, já apresentados por Sarquis (1999); e Sarquis; Felli (2002).

A maioria destes trabalhadores $(51,8 \%)$, relata um ritmo acelerado e exaustivo com freqüência trabalhando em média 12 horas ao dia, o que pode comprometer a saúde destes trabalhadores. As exposições às sobrecargas de trabalho podem comprometer a saúde tendo repercussão na qualidade de vida destes trabalhadores. Com o ritmo acelerado de trabalho, haverá uma maior exposição às cargas e como conseqüência um processo de trabalho comprometido, o que potencializa o acontecimento de acidentes de trabalho conforme já estudados por Sarquis; Felli(2002); Meirelles(1997); Dall'agnoll et al. (1999).

$$
\text { Uma pequena amostra } 26,8 \% \text { de }
$$

trabalhadores sofreu algum tipo de acidente de trabalho nos dois últimos anos. Estes dados são encontrados no processo de trabalho que estão inerentes ao trabalho. Gostaríamos de ressaltar que a instituição possui um serviço de educação continuada atuante e participativa, com a realização de treinamento períodos realizados pela Comissão Interna de Prevenção de Acidentes CIPA e também outros procedimentos educativos.

Entre os acidentes mais freqüentes entre estes trabalhadores de enfermagem, encontramos o ferimento por instrumento perfurocortante em $73,2 \%$ dentre todos os outros acidentes. Estes dados vêm corroborar com os estudos realizados por Sarquis; Felli(2002); Bolick et al (2000); Rodrigues et al. (1997); Sarquis (1999), que também encontraram entre os trabalhadores de enfermagem uma maior exposição a este tipo de acidente.

Encontramos também que $89,4 \%$ destes trabalhadores apresentam um grave comprometimento da saúde no que diz respeito às lesões osteo-articulares como as cervicodorsolombalgias. O comprometimento da saúde expresso nas cervicodorsolombalgias está relacionado ao transporte de pacientes e também na mobilização do cliente no leito hospitalar. Este valor percentual representa uma grande sobrecarga de trabalho comprometendo a saúde do trabalhador. Estes dados vêm corroborar com os estudos de Sarquis; Felli (2002); Sarquis (1999) e Meirelles (1997). Estas autoras ressaltam para o desenvolvimento de medidas de intervenção por parte das instituições em relação aos procedimentos de segurança no trabalho, bem como medidas de intervenção no processo de trabalho para que esta sobrecarga venha diminuir, melhorando, portanto a diminuição aos agravos de saúde destes trabalhadores submetidos a estes desgastes.

Um outro fator que soma ao desgaste no processo de trabalho com uma maior exposição aos acidentes de trabalho é a dupla jornada de trabalho, que foi relatada por $50 \%$ da população estudada, já estudados por Alves; Jouclas (1997); e Meirelles (1997).

Em relação à adequação da escala de trabalho, $75 \%$ dos trabalhadores de enfermagem relatam que está adequada. Os estudos sobre a importância da organização no trabalho já foram estudados por Sarquis (1999); Marquis; Huston 
(1999); Kurcgant (1991) e outros pesquisadores, que afirmam ser a organização de trabalho um fator determinante para as condições adequadas no ambiente de trabalho, bem como melhorando a qualidade de vida dos trabalhadores.

Podemos observar que $55,4 \%$ destes trabalhadores estão expostos a fadigas físicas, mentais e aos acidentes de trabalho devido às jornadas de trabalho prolongadas. De acordo com Grandjean (1998), esta sobrecarga de trabalho é prejudicial para a produção, favorecendo o absenteísmo. Encontramos a dupla jornada de trabalho entre $50 \%$ destes trabalhadores, o que sabemos que pode comprometer a saúde do trabalhador expondo-o a riscos mais freqüentes no ambiente de trabalho pelo desgaste físico e sobrecarga no ambiente de trabalho.

Constatamos um comprometimento na saúde destes trabalhadores desencadeado pelo excesso de esforço físico no processo do trabalho constatado pelas cervicodorsolombalgias $(89,4 \%)$ e com presença de úlceras varicosas em membros inferiores em $41 \%$ destes trabalhadores. Estes agravos com a saúde podem comprometer 0 processo saúde-doença e necessitam de atenção por parte da instituição e dos profissionais que nela militam. Estes dados vêm ao encontro com os estudos já realizados por Meirelles (1997) e Sarquis; Felli (2002).

\section{CONSIDERAÇÕES FINAIS}

Recomendamos enquanto pesquisadoras uma maior atenção ao processo de trabalho quanto ao esforço físico desenvolvido por estes trabalhadores em seu local de trabalho, pois ainda a exposição às doenças ocupacionais como lesões ósteo-articulares e cervicodorsolombalgias é muito elevada para um grande número de trabalhadores.

Este estudo indica a necessidade de intervenções por parte das instituições, chefias e para os próprios trabalhadores com o objetivo de minimizar a exposição aos riscos de acidente de trabalho e de adquirir doenças infecto-contagiosas. Entendemos que uma parcela está sobre os responsáveis da instituição em relação às formas organizacionais no que diz respeito à jornada de trabalho e estrutura física da organização, porém também sabemos que a outra parcela está sobre a responsabilidade dos trabalhadores que nesta instituição atuam.

\section{REFERÊNCIAS}

ALVES, M; JOUCLAS, M.G. O cotidiano do trabalho dos auxiliares: uma dimensão de sofrimento. Rev. Cogitare Enf. Curitiba, v.2, n.2, p.83-88, jul-dez. 1997.

BRASIL. Ministério da Saúde. Secretaria de Políticas de Saúde. Saúde do Trabalhador. Departamento de Atenção Básica. Brasília, 2002.

BOLICK, D. et al. Segurança e controle de infecção. Rio de Janeiro: Reichmann e Afonso, 2000.

CARVALHO, A. I. et al. Gestão em saúde: curso de aperfeiçoamento para dirigentes municipais de saúde: programa de educação à distancia. Rio de Janeiro: Fiocruz,1998.

CARVALHO, D. V; LIMA, E. D. R. P. Sintomas físicos de estresse na equipe de enfermagem de um centro cirúrgico. Nursing, São Paulo, ano 4, n. 34, p 34-37, 2001.

COLLET, N; ROZENDO, C. A. As transformações no mundo do trabalho e as implicações para a enfermagem. Rev. Cogitare Enf., Curitiba, v.3, n.2, p. 100-104, jul-dez. 1998.

DALL'AGNOL, L. A. et al. Prevenção de exposição a cargas de trabalho e riscos de acidentes em Pelotas, RS (Brasil). Rev. Saúde Pública. São Paulo, v. 33,n.2,p.23-26, abril, 1999.

DEJOURS, C. A. A loucura do trabalho: estudo de psicopatologia do trabalho. 5. ed. São Paulo: Cortz-Obore, 1992.

DISSENHA, C. F. Qualidade de vida do trabalhador de enfermagem: perfil dos auxiliares de enfermagem da unidade de saúde Vila Leão. 1999. Monografia (Especialização em saúde do trabalhador) - Setor de Ciências Biológicas e da Saúde, Universidade Federal do Paraná, Curitiba.

EGRY, E. Y. Saúde Coletiva: construindo um novo método em enfermagem. São Paulo: Ícone, 1996. 
FLARESSO, W. O Corpo e o Trabalho: incursões sobre qualidade de vida e ginástica laboral. 1998. Monografia (Especialização em Saúde do Trabalhador) - Setor de Ciências Biológicas e da saúde, Universidade Federal do Paraná, Curitiba.

GRANDJEAN, E. Manual de ergonomia: adaptando o trabalho ao homem. Porto Alegre: Artes Médicas, 4. ed. 1998.

KURCGANT, P. Administração em enfermagem. São Paulo, EPU, 1991.

LAURELL, A.C.; NORIEGA, M. Processo de produção e saúde: trabalho e desgaste do operário. São Paulo: Hucitec,1989.

MARQUIS, B. L; HUSTON, C. Administração e liderança em enfermagem: teoria e aplicação. 2 . ed. Porto Alegre: Artes Médicas Sul, 1999.

MEIRELLES, B,H,S. A enfermagem frente aos riscos do ambiente hospitalar. Rev. Cogitare Enf Curitiba, v.2, n.1, p.21-24, 1997.

NOGUEIRA, M.J. de C. "Níveis de prevenção em enfermagem do trabalho" Rev. Bras. Saúde. Ocup. V. 11, n. 43. p. $57-61,1983$.

RODRIGUES, E. A. et al. Infecção hospitalares: prevenção e controle. São Paulo: Sarvier,1997.

SARQUIS, L. M. Acidentes de trabalho com instrumentos perfurocortantes: ocorrência entre os trabalhadores de enfermagem. 1999. Dissertação (Mestrado), Universidade de São Paulo. São Paulo.

SARQUIS, L. M; FELLI, V. E. A. Acidentes de trabalho com instrumento perfurocortantes entre os trabalhadores de enfermagem. Rev. Esc. de enf. USP. São Paulo, v.36, n.3, p. 222-230, 2002.

VENÂNCIO, C. A. Qualidade de vida no trabalho $X$ Estressores freqüentes a que estão sujeitos os profissionais de enfermagem que atuam no serviço de transplante de Medula Óssea. 2000. Monografia (Especialização em saúde do trabalhador) - Setor de Ciências da Saúde, Universidade Federal do Paraná. Curitiba.

ENDEREÇO DAS AUTORAS: Av. Iguaçu, 2666 - ap. 1201 Curitiba/PR 80240-030 m.sarquis@brturbo.com 